\title{
The prevalence and mode of inheritance of median diastema in the Sinhalese
}

\author{
"Upul Dissanayake', MS Chandrasekara², ER Wikramanayake'.
}

The Ceylon Journal of Medical Science 2003: 46: 01-06

\section{Abstract}

Prevalence and mode of inheritance of median diastema has been studied in a population of 1018 Sinhalese ( 551 males and 467 females, age range 20 to $30 \mathrm{yrs}$ ). Median diastema is a visually detectable gap or space of more than $1 . \mathrm{mm}$ between the upper permanent central incisors $\Perp 1$. A metal blade $1 \mathrm{~mm}$ thick was used as a measuring gauge. If the gauge passed through without any interference when inserted at right angles to the surface of $\underline{11}$, the trait was recorded as present. The prevalence of median diastema in the Sinhalese was compared with that reported for other population groups. Fifteen subjects who had median diastemas with high frenum were randomly selected as probands for construction of pedigrees. The most probable mode of inheritance was determined by using different models of inheritance. The findings were confirmed by assessing the frequency of distribution of the trait among individuals in the pedigrees using the simple counting method. The prevalence of median diastema in the Sinhalese is $9 \%$ and the mode of inheritance in the pedigrees studied was autosomal dominant with full penetrance.

Key words: Median diastema, Mendalian inheritance

\section{Introduction}

Median diastema is a visually detectable gap or space of more than one $\mathrm{mm}$ in width between the upper first permanent central incisors which continues to exist throughout adult life $(1,2,3)$. Median diastemas are common during the development of the dentition. Such median diastemas usually close completely after the eruption of the permanent maxillary teeth. The existence of a midline space in some of them, throughout adult life after establishment of the permanent dentition is labeled median diastema $(1,2)$. This dental anomaly is a recognized clinical entity in the Sinhalese because it is an aesthetic problem. However, in other populations the frequency of this trait is so high for it to be considered as the norm $(1,4)$. Several aetiological factors other than genetic have been identified for this trait $(1,2,5)$. These include the absence of lateral incisors, presence of peg shaped lateral incisors, the discrepancy in the ratio of the total mesio-distal diameter of the dentition and the dental arch and the position and attachment of the labial frenum $(4,5)$. It has also been shown that the presence of mesiodens may also lead to median diastema $(6,7)$.

Only a few studies have been reported on the prevalence of median diastema in different population groups(8). Studies on mode of inheritance of the trait are even less. Previous reports on the mode of inheritance of median diastema have also given conflicting results(9). The aim of the present study was to determine the prevalence of median diastema and establish the mode of inheritance of the trait in the Sinhalese.

\section{Population and Method}

The study sample consisted of undergraduates between 20 to 30 years of age from the University of Peradeniya. Individuals with mixed parentage were excluded from the sample at the preliminary stage. Subjects with associated factors which influence the occurrence of median diastema such as those who had undergone orthodontic treatment, extractions, restorations distorting the morphology of the teeth and those median diastemas due to endogenous tongue thrust, lip trap, and generalized spacing were also excluded from the sample. The sample for the prevalence of median diastema totaled 1018 (551 males and 467 females).

1 Division of General Pathology, Faculty of Dental Sciences, University of Peradeniya. Peradeniya., 2 Department of Anatomy, Faculty of Medicine, 3 Emeritus Professor, University of Peradeniya. Peradeniya.

- Corresponding author upulbd@pdn.ac.lk 


\section{Detection of median diastema}

For the identification of median diastema, a small metal blade $1 \mathrm{~mm}$ thick was used. The metal blade was inserted between the two upper permanent central incisors in the plane at right angles to the labial surface of the teeth. The trait was considered absent in subjects who had spaces where the metal blade did not pass through. When the blade passed through the gap without any interference, the trait was recorded as present. Subjects with the trait were further categorized according to the position of the attachment of the labial frenum as high or low. When the frenum was attached more than $2 \mathrm{~mm}$ away from the inter dental papilla, it was considered as high whilst a distance of less than $2 \mathrm{~mm}$ was considered low.

\section{Pedigree}

Fifteen probands were randomly selected from $53(5.2 \%)$ individuals who had median diastemas with high frenal attachment. Median diastemas with low frenal attachments were not included in the sample, as the space in such cases may be due to the interposition of the frenum rather than genetic predisposition. Pedigree charts were drawn using the proband as the informant. Home visits were made to examine and record the trait in the individuals on the pedigree charts. The pedigree charts were cross checked for errors.

\section{Results}

Table I shows the number and percentage of males and females having median diastema with high and low frenal attachment. Of 551 males $27(4.9 \%)$ and $20(3.7 \%)$ had median diastema with high and low frenal attachment respectively. Of 467 females $26(5.6 \%)$ and $18(3.9 \%)$ had median diastema with high and low frenal attachment respectively. A total of $47(8.6 \%)$ males and $44(9.4 \%)$ females had median diastema irrespective of the position of the frenal attachment. There was no significant difference in the prevalence of median diastema between males and females indicating that there is no sexual dimorphism in the trait $(p>0.05)$. Of the total sample of 1018 subjects, 91 had median diastema giving an overall prevalence of $9 \%$.
Table 2 gives the total number of subjects on the informative side of the pedigree and number of subjects positive and negative for the trait for each pedigree. Of a total of 234 informative subjects 121 (63 males 58 females) had the trait and 113 subjects did not have the trait. There was no significant difference in the prevalence of the trait between males and females $(p>0.05)$. The pooled data gives a ratio of positive to negative individuals for median diastema as 121:113.

\section{Discussion}

A comprehensive cross sectional study of median diastema over all age groups from infancy to old age, was carried out by Lindsey(10). He observed the prevalence of $67 \%$ in children with only the permanent maxillary incisors erupted, $40 \%$ in children with permanent maxillary and lateral incisors erupted and $27 \%$ in children with permanent maxillary central and lateral incisors and canines erupted. A gradual reduction of median diastema occurs with advancing age in children up to the completion of the permanent dentition(11).

The prevalence of median diastema varies in different population groups. In the earliest study, Taylor reported that the prevalence of median diastema was $7 \%$ among Californian children ranging in age of 12-18 years(12). In two studies on Caucasian children in the United Kingdom a prevalence of $6.8 \%$ and 3.5 to $4 \%$ was reported by Weyman and Gardiner $(10,13)$. In a comparative study of children Horowitz reported a prevalence of median diastema of $8 \%$ for Caucasians and $19 \%$ for Negroids(14). In a comparative study of adults, Lavelle reported a prevalence of $3.5 \%, 3.4 \%$ and $5.2 \%$ for Caucasians, Mongoloids and Negroids respectively(8). Mc Vay and Latta studied median diastemas radiologically considering a space of more than $0.5 \mathrm{~mm}$ as positive for the trait(15). They observed a prevalence of $9.6 \%, 12.5 \%$ and $16.3 \%$ for median diastema of 0.5 to $1.49 \mathrm{~mm}$ for Caucasians, Mongoloids and Negroids respectively. In the same study a prevalence of $10.4 \%, 7.6 \%$ and $12.9 \%$ was observed for median diastema of more than $1.5 \mathrm{~mm}$ for Caucasians, Mongoloids and Negroids respectively. The high 
prevalence for all racial groups in the above study may be due to the radiological method enabling the detection of median diastema of $0.5 \mathrm{~mm}$. However, the prevalence for the Caucasian-Mongoloid groups is similar to the Negroids, being relatively higher as in the earlier studies of Horowitz and Levalle who used the direct method(8,14).

In the present study, the prevalence of median diastema in the Sinhalese is $9 \%$. The prevalence in the Sinhalese cannot be directly compared with those of other population studies already referred to due to differences in methodology, variations in the cut off value for the detection of median diastema and the dissimilarity in chronological stratification of the population groups.

The mode of inheritance was studied by drawing 15 pedigree charts(16). A pedigree chart is given in Figure 1. The proband always had a parent also positive for the trait. Eight of the probands inherited the trait from the father and other seven inherited it from the mother, indicating complete penetrance of the gene.

In 6 pedigrees the trait was transmitted from father to daughter. Transmission was from father to son in 2 and from mother to daughter in 4 . The mother trạnsmitted the trait to the son in only 3 pedigrees excluding $X$ linked recessive inheritance.

The pedigrees were further analyzed for frequency diștribution using the simple counting method(17). There were 63 males and 58 females positive for the trait. Sixty three males and 50 females were negative for the trait. The ratio for both males and females positive for the trait was 63:58 and that for males and females negative for the trait was 63:50. As there was no significant difference between males and females for both trait positive and trait negative ratios, the data were pooled together. Of 234 : informative subjects, 121 were positive for the trait and 113 were negative for the trait irrespective of the sex. With an autosomal dominant mode of inheritance 117 subjects would be expected to be positive from a total of 234 giving a ratio of $1: 1$ irrespective of the sex. The chi square test showed that the observed ratio of $121: 113$ is not significantly different from expected ratio of $\mathrm{I}: \mathrm{I}$. These findings, together with the observations mentioned above, clearly demonstrate that the transmission of median diastema to follow an autosomal dominant pattern with full penetrance.

In conclusion the results of the present study has established the prevalence of median diastema in the Sinhalese as $9 \%$ and that the mode of inheritance as autosomal dominant with full penetrance.

\section{References}

1. Becker A. The median diastema. Dental Clinics of North America 1978; 22: 685-700.

2. Hung WJ and Creath $\mathrm{CJ}$. The midline diastema. A review of its etiology and treatment. Pediatric Dentistry 1995; 17: 171-179.

3. Chu FC, Siu AS, Newsome PR, Weis H. Man agement of median diastema. General Dentistry 2001; 49:282-287.

4. Ferguson MWJ. Pathogenesis of abnormal midline spacing of human central incisors. British Dental Journal 1983. 154:212-218.

5. Dewel BF. The labial frenum, midline diastema and palatine papilla: a linical analysis. Dental Clinics of North America 1966; 10: 175-184.

6. Ferguson NC, Worth HM, Dillabaugh $\mathrm{GH}$. An investigation of the occurrence of diastema and supernumerary teeth. Journal of American Dental Association 1973; 8: 409-410.

7. Yamaoka M, Furusawa K, Yasuda K. Effect of median anterior supernumerary impacted teeth on diastema. Oral Surgery Oral Medicine Oral Pathology Oral Radiology Endodontics 1995; 80:252-257.

8. Lavelle CLB. The distribution of diastemas in different human population samples. Scandinavian Journal of Dental Research 1970; 78 : 530-534. 
9. McKusick VA. Mendelian Inheritance in Man: Catalogs of autosomal dominant, autosomal recessive and sex link phenotypes. John Hopkins University Press 1990.

10. Lindsey D. The upper midline space and its relation to the labial frenum in children and adults. British Dental Journal 1977; 143: 327-332.

11. Weyman J. The incidence of median diastema during the eruption of the permanent teeth. The Dental Practitioner 1967; 17: 276-278.

12. Taylor JE. Clinical observations relating to the normal and abnormal frenum labii superians. American Journal of Orthodontics 1939;25:646.
13. Gardiner JH. Midline spaces. The Dental Practitioner 1967: 17: 287-297.

14. Horowitz HS. A study of occlusal relations in 12 year old Caucasian and Negroid children. International Dental Journal 1970: 20: 593-597.

15. McVay J and Latta GH. Incidence of the maxillary midline diastema in adults. The Journal of Prosthetic Dentistry 1984; 52: 809-811.

16. Mueller RF, Young ID. Emery's elements of medical genetics. Churchill Livingston. 1995: $77-90$.

17. Stern C. Principles of human genetics. W.H. Freeman and Company 1960; 90-94.

Table 1. Number and percentage of subjects having median diastema with high and low frenal attachments. The percentages are indicated in parentheses.

\begin{tabular}{|l|c|c|c|c|}
\hline Gender & Number & $\begin{array}{c}\text { Median diastema } \\
\text { with high frenum }\end{array}$ & $\begin{array}{c}\text { Median diastema } \\
\text { with low frenum }\end{array}$ & Total \\
\hline Male & 551 & $\begin{array}{c}27 \\
(4.9 \%)\end{array}$ & $\begin{array}{c}20 \\
(3.7 \%)\end{array}$ & $\begin{array}{c}47 \\
(8.5 \%)\end{array}$ \\
\hline Female & 467 & $\begin{array}{c}26 \\
(5.6 \%)\end{array}$ & $\begin{array}{c}18 \\
(3.9 \%)\end{array}$ & $\begin{array}{c}44 \\
(9.4 \%)\end{array}$ \\
\hline Total & 1018 & $\begin{array}{c}53 \\
(5.2 \%)\end{array}$ & $\begin{array}{c}38 \\
(3.7 \%)\end{array}$ \\
\hline
\end{tabular}




\begin{tabular}{|c|c|c|c|c|c|c|c|c|c|c|}
\hline \multirow{2}{*}{$\begin{array}{l}\text { Pedigree } \\
\text { number }\end{array}$} & \multicolumn{3}{|c|}{ Informative subjects } & \multicolumn{3}{|c|}{ Positive subjects } & \multicolumn{3}{|c|}{ Negative subjects } & \multirow{2}{*}{$\begin{array}{r}\text { Ratio } \\
\text { +ve:-ve }\end{array}$} \\
\hline & Male & Female & Total & Male & Female & Total & Male & Female & Total & \\
\hline \begin{tabular}{|l|}
1 \\
\end{tabular} & 7 & 10 & 17 & 4 & 5 & 9 & 3 & 5 & 8 & $9: 8$ \\
\hline 2 & 7 & 9 & 16 & 4 & 5 & 9 & 3 & 4 & 7 & $9: 7$ \\
\hline 3 & 10 & 11 & 21 & 5 & 6 & 11 & 5 & 5 & 10 & $11: 10$ \\
\hline 4 & 8 & 7 & 15 & 4 & 4 & 8 & 4 & 3 & 7 & $8: 7$ \\
\hline 5 & 5 & 8 & 13 & 4 & 3 & 7 & 5 & 1 & 6 & $7: 6$ \\
\hline \begin{tabular}{|l}
6 \\
\end{tabular} & 9 & 6 & 15 & 5 & 2 & 7 & 4 & 4 & 8 & $7: 8$ \\
\hline 7 & 6 & 9 & 15 & 4 & 2 & 6 & 5 & 2 & 7 & $8: 7$ \\
\hline 8 & 7 & 5 & 12 & 4 & 4 & 8 & 4 & 2 & 6 & $6: 6$ \\
\hline 9 & 8 & 8 & 16 & 3 & 3 & 6 & 4 & 4 & 8 & $8: 8$ \\
\hline 10 & 9 & 4 & 13 & 4 & 4 & 8 & 5 & 1 & 6 & $7: 6$ \\
\hline 11 & 6 & 8 & 14 & 4 & 3 & 7 & 5 & 2 & 7 & $7: 7$ \\
\hline 12 & 10 & 8 & 18 & 5 & 4 & 9 & 4 & 5 & 9 & $9: 9$ \\
\hline 13 & 9 & 6 & 15 & 4 & 4 & 8 & 2 & 5 & 7 & $8: 7$ \\
\hline 14 & 7 & 12 & 19 & 4 & 6 & 10 & 6 & 3 & 9 & $10: 9$ \\
\hline 15 & 9 & 6 & 15 & 5 & 2 & 7 & 4 & 4 & 8 & $7: 8$ \\
\hline Total & 117 & 117 & 234 & 63 & 58 & 121 & 63 & 50 & 113 & $121: 113$ \\
\hline
\end{tabular}


I

II

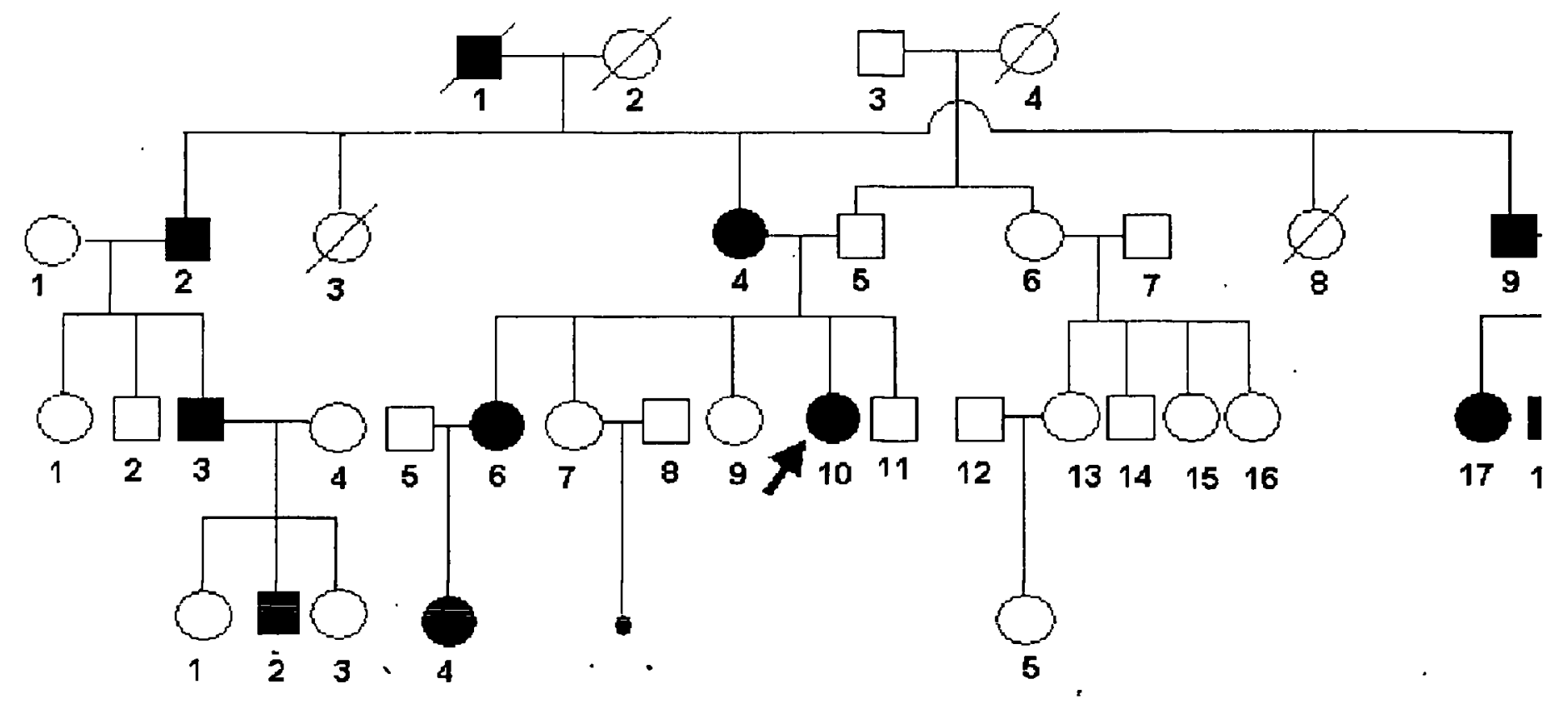

IV

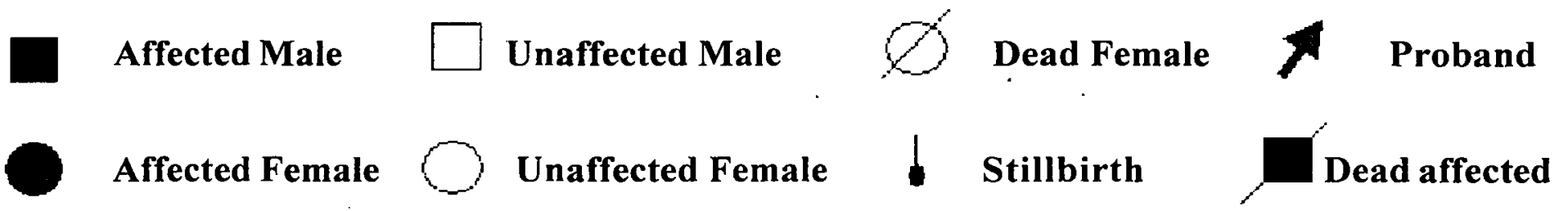

- I = Generation I II = Generation II III = Generation III $\quad$ IV $=$ Generation IV

Figure 1. Pedigree chart of a family showing autosomal dominant mode of inheritance 